\title{
THE EFFECTS OF CHROMIUM AND NICKEL ON THE PASSIVATION BEHAVIOR OF SPUTTER-DEPOSITED W-Cr-Ni ALLOYS IN 12 M HCL SOLUTION
}

\author{
Jagadeesh Bhattarai* \\ *Central Department of Chemistry, Tribhuvan University, Kirtipur, Kathmandu, Nepal.
}

\begin{abstract}
The passivity of sputter-deposited ternary W-Cr-Ni alloys is investigated by immersion tests and electrochemical measurements in $12 \mathrm{M} \mathrm{HCl}$ solution at $30^{\circ} \mathrm{C}$, open to air. Particular attention is paid to the effects of alloying elements to the corrosion behavior. All the examined amorphous or/and nanocrystalline W-Cr-Ni alloys are passivated spontaneously even in an aggressive environment of $12 \mathrm{M} \mathrm{HCl}$, and hence these alloys showed higher corrosion resistance than those of alloyconstituting elements. The chromium addition suppresses the anodic dissolution current because of the formation of tetravalent chromium oxyhydroxide having a relatively high activity for both cathodic oxygen and hydrogen reduction with a consequent ennoblement of the open circuit potential. The ennoblement of the open circuit potential leads to the formation of the passive chromium oxyhydroxide film. It is, therefore, considered that the addition of chromium improves synergistically the corrosion resistance and passivating abilities of the sputter-deposited binary W-Ni alloys in $12 \mathrm{M} \mathrm{HCl}$ solution.
\end{abstract}

Keywords: Sputter-deposition; Ternary W-Cr-Ni alloys; Corrosion-resistant; Electrochemical measurements.

\section{INTRODUCTION}

The chemically homogeneous single-phase nature of amorphous or nanocrystalline alloys is generally responsible for their high corrosion resistance owing to the formation of uniform protective passive films those are able to separate bulk of alloys from aggressive environments. From the corrosion point of view they can be considered as homogeneous alloys. Accordingly, the sputter-deposited alloys consisting of either amorphous or/and nanocrystalline single-phase are chemically homogeneous, and hence are interesting in the view of corrosion resistance.

In recent years, the present author has been reported that the sputter deposition of tungsten with titanium ${ }^{1-5}$,

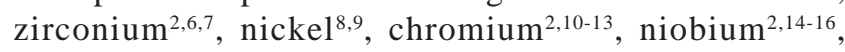
tantalum $^{2,17}$ and molybdenum ${ }^{8,18}$ is effective in preparing amorphous or/and nanocrystalline tungsten-base binary alloys with a high corrosion resistance. The high corrosion resistance of these sputter-deposited alloys was based on spontaneous passivation in concentrated hydrochloric acid solutions at $30^{\circ} \mathrm{C}$.

The sputter deposition is one of the main methods of vapor quenching techniques and used as one of the potential methods for the preparation of varieties of amorphous or nanocrystalline alloys ${ }^{19}$. In recent years, this technique is known to form amorphous or nanocrystalline structures over the widest composition range among the various methods. Therefore, the use of sputtering is quite suitable for tailoring of the corrosion-resistant metastable alloys. Furthermore, even if amorphous alloys are not formed by the sputter deposition technique, the alloys thus prepared are always composed of nanocrystals with very fine grains and sometimes behaves similar to the single-phase amorphous alloys. In particular, sputtering is suitable for forming alloys when the boiling point of one of the alloying component is lower than the melting point of the other alloying components, because sputter deposition does not require melting of alloying components for the alloy formation. For instance, boiling points of chromium $\left(2670^{\circ} \mathrm{C}\right)$ and nickel $\left(2900^{\circ} \mathrm{C}\right)$, which are lower than the melting point of tungsten $\left(3420^{\circ} \mathrm{C}\right)$. However, successful attempts have been reported to prepare single-phase amorphous or /and nanocrystalline $\mathrm{W}-\mathrm{Ni}^{8,9}$ and $\mathrm{W}-\mathrm{Cr}^{10}$ alloys by using the advantages of sputtering.

Tungsten and chromium are regarded as very effective alloying elements for enhancing the corrosion resistance of the alloys in aggressive environments. In particular, chromium

Author for Correspondence: Dr. Jagadeesh Bhattarai, Central Department of Chemistry, Tribhuvan University, Kirtipur, Kathmandu, Nepal. E-mail:bhattarai_05@yahoo.com. 
is one of the most effective alloying elements to provide a high passivating ability for conventional steels. In this context, it has been reported that only small amount of tungsten addition (that is, less than 10 at\%) was enough to cause spontaneous passivation of the sputter-deposited nanocrystalline $\mathrm{W}$-Cr alloys even in $12 \mathrm{M} \mathrm{HCl}$ and these alloys showed about five orders of magnitude lower corrosion rate than the corrosion rate of chromium metal, and about one order of magnitude lower corrosion rate than that of tungsten ${ }^{10,13}$. Similarly, it has been reported that the corrosion resistance of the sputter-deposited amorphous or/and nanocrystalline W-Ni alloys were passivated spontaneously and observed significantly high corrosion resistance in aggressive environments $\mathrm{s}^{8,9,20-22}$. The corrosion rates of the sputter-deposited W-Ni alloys cannot exceed that of tungsten although the addition of tungsten greatly enhances the corrosion resistance of nickel in $12 \mathrm{M} \mathrm{HCl}$. On the other hand, it has been reported that the molybdenum addition to the sputter-deposited $\mathrm{Cr}-\mathrm{Ni}^{23}$ and $\mathrm{Al}-\mathrm{Cr}^{24}$ alloys results in spontaneous passivation in hydrochloric acid solutions and suppresses the dissolution because of the formation of tetravalent molybdenum. Accordingly, it might be expected that corrosion-resistant of tungsten is enhanced by alloying with chromium and nickel.

The present work aims to prepare corrosion-resistant ternary $\mathrm{W}-\mathrm{Cr}-\mathrm{Ni}$ alloys by the sputter-deposition method, and to clarify the effects of chromium and nickel additions on the passivation behavior of these alloys in $12 \mathrm{M} \mathrm{HCl}$ solution at $30^{\circ} \mathrm{C}$, open to air.

\section{MATERIALS AND METHODS}

Direct current (D. C.) magnetron sputtering was used for the preparation of ternary W-Cr-Ni alloys. The target was composed of a 99.95\% pure tungsten disk of $100 \mathrm{~mm}$ diameter and $6 \mathrm{~mm}$ thickness, on the erosion region of which 99.95\% pure chromium disks of $20 \mathrm{~mm}$ diameter and 99.95\% pure nickel plates having a small square shape and about $2 \mathrm{~mm}$ in thickness were symmetrically placed. The composition of the sputter deposits was changed by changing the numbers of chromium and nickel disks on the tungsten disk. Glass plates were used as substrates which were rinsed by immersion in water containing a commercial detergent for the cleaning at about $75^{\circ} \mathrm{C}$. The sputtering apparatus and conditions used were the same as those described elsewhere ${ }^{2}$.

An electron probe microanalysis (EPMA) was used to determine the composition of the sputter deposits. The structure of the sputter-deposited ternary W-Cr-Ni alloys was confirmed by glancing incident X-ray diffractometer (XRD) with CuK $\alpha$ radiation at $\alpha-2 \theta$ mode. The apparent grain size of the alloys was estimated from the full width at half maximum (FWHM) of the most intense reflection according to Scherrer's relation $^{25} ; \mathrm{t}=0.9 \lambda / \beta \cos \theta$, where $\mathrm{t}$ is the apparent grain size, $\lambda$ is the $\mathrm{X}$-ray wavelength $(0.15148 \mathrm{~nm}$ for $\mathrm{CuK} \alpha), \beta$ is the FWHM in radian and $\theta$ is the diffraction angle.

Prior to corrosion tests and electrochemical measurements the surface of the alloy specimens was polished mechanically with silicon carbide paper up to No. 1500 in cyclohexane, rinsed with acetone and dried in air in order to obtain reproducible results by removal of the air formed oxide film on as-sputtered alloys.

Corrosion rates of the sputter-deposited ternary W-Cr-Ni alloys and tungsten metal were estimated from the weight loss after immersion for $168 \mathrm{~h}$ in $12 \mathrm{M} \mathrm{HCl}$ at $30^{\circ} \mathrm{C}$, open to air. For nickel and chromium metals the corrosion rate was estimated after immersion for $7 \mathrm{~h}$ in $12 \mathrm{M} \mathrm{HCl}$ solution. Potentiodynamic cathodic and anodic polarization curves were measured in $12 \mathrm{M} \mathrm{HCl}$ solution after immersion for $1 \mathrm{~h}$ when the open circuit potential became almost steady. A platinum mesh and a saturated calomel electrode (SCE) were used as counter and reference electrodes, respectively. All the potential given in this paper are relative to SCE.

\section{RESULTS AND DISCUSSION}

The structure of the sputter-deposited W-Cr-Ni alloys was identified by X-ray diffraction (XRD) techniques. The XRD patterns of the ternary W-Cr-Ni alloys including binary W15Ni alloy are shown in Fig. 1. Alloy compositions hereafter are all denoted in atomic percentage. The W-63Cr-15Ni and W67Cr-9Ni alloys show halo patterns typical of the amorphous structure. However, the W-42Cr-5Ni, W-75Cr-4Ni and W-15Ni alloys consist of a mixture of amorphous and crystalline structures. In general, the characteristic interatomic spacing of the supersaturated solid solutions of the binary alloys varies almost linearly with concentration of the alloy-constituting elements ${ }^{2}$. From the XRD patterns of the ternary W-Cr-Ni alloy as shown in Fig. 1, a continuous shift of the most intense

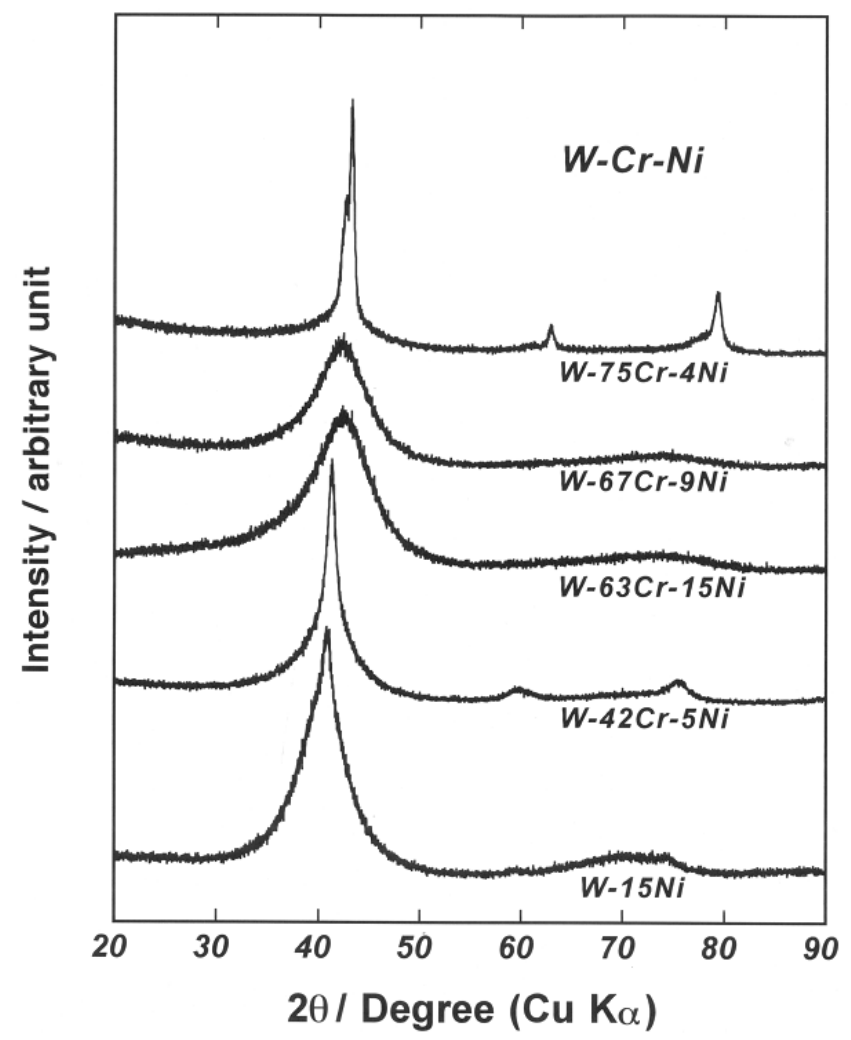

Figure 1: X-ray diffraction patterns of sputter-deposited ternary WCr-Ni alloys including binary W-15Ni alloy. 
reflection of the alloy is observed from 110 reflection of the bcc $\alpha$-tungsten phase to the 110 reflection of the bcc chromium phase when the chromium content in the alloys increases which is clearly shown in Fig. 2 also.

Furthermore, though some of the sputter-deposited ternary W-Cr-Ni alloys show a crystalline structure broadening of the peak is clearly observed with increasing nickel content in the alloy as shown in Fig. 1. Therefore, the apparent grain size of the alloys was estimated from the full width at half maximum (FWHM) of the most intense reflection using Scherrer's relation ${ }^{25}$. Table 1 shows the estimated apparent grain size and structures for the sputter-deposited ternary W-Cr-Ni alloys including tungsten, chromium and nickel metals. The apparent grain sizes of the W-18Cr-14Ni, W-63Cr$15 \mathrm{Ni}$ and $\mathrm{W}-67 \mathrm{Cr}-9 \mathrm{Ni}$ alloys are 1.6, 1.6 and $1.5 \mathrm{~nm}$, respectively, which is only a little larger than the size of atom groups supposed to exist in liquid metals. Accordingly, the W-18Cr$14 \mathrm{Ni}, \mathrm{W}-63 \mathrm{Cr}-15 \mathrm{Ni}$ and $\mathrm{W}-67 \mathrm{Cr}-9 \mathrm{Ni}$ alloys are regarded as amorphous alloys. On the other hand, the apparent grain size of the $\mathrm{W}-42 \mathrm{Cr}-5 \mathrm{Ni}$ and $\mathrm{W}-75 \mathrm{Cr}-4 \mathrm{Ni}$ alloys is of the order of 3.5-10.2 nm. Consequently, the sputter-deposited ternary WCr-Ni alloys are composed of supersaturated amorphous or/ and nanocrystalline solid solutions of the alloy-constituting elements (that is, tungsten, chromium and nickel).

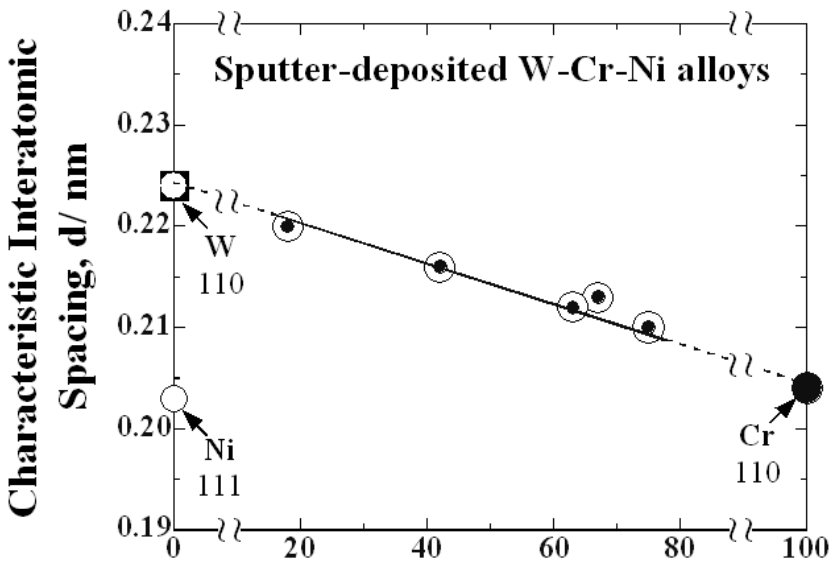

Alloy Chromium Content / at \%

Figure 2: The change in characteristic interatomic spacing of the sputter-deposited ternary W-Cr-Ni alloys as a function of alloy chromium content. The interatomic spacing of the tungsten, chromium and nickel metals are also shown for comparison.

Figure 3 shows the composition-structure diagram of the sputter-deposited binary and ternary tungsten-base alloys. This figure reveals that the binary W-Ni alloys, and ternary $\mathrm{W}-\mathrm{Cr}-\mathrm{Ni}$ alloys containing 9 at\% or more content of nickel are apt to form amorphous structure, except for the binary W$\mathrm{Cr}$ and $\mathrm{Cr}-\mathrm{Ni}$ alloys because they do not satisfy the prerequisite for easy formation of the amorphous structure. The sputter-deposited binary $\mathrm{W}$-Cr alloys were not amorphized $^{2,10}$ because the alloys are characterized by the positive mixing enthalpy and a smaller difference in atomic size of tungsten and chromium ${ }^{26}$. Similarly, the sputterdeposited Cr-Ni alloys were also not amorphized since the atomic sizes of chromium and nickel are almost the same, although the mixing enthalpy of these alloys is $-27 \mathrm{~kJ} / \mathrm{mol}^{26}$. Furthermore, it is noteworthy to mention here that it had
Table 1: Chemical composition, structure and apparent grain size of the sputter-deposited ternary $\mathrm{W}$-Cr-Ni alloys including alloy-constituting elements.

\begin{tabular}{|l|l|c|}
\hline Name of alloy & \multicolumn{1}{|c|}{ Structure } & $\begin{array}{c}\text { Apparent grain } \\
\text { size (nm) }\end{array}$ \\
\hline W-18Cr-14Ni & Amorphous & 1.6 \\
\hline W-42Cr-5Ni & Amor. + Nanocryst. & 3.5 \\
\hline W-63Cr-15Ni & Amorphous & 1.6 \\
\hline W-67Cr-9Ni & Amorphous & 1.5 \\
\hline W-75Cr-4Ni & Amor. + Nanocryst. & 10.2 \\
\hline W-15Ni & Amor. + Nanocryst. & $2.5^{*}$ \\
\hline Tungsten & Nanocrystalline & 20.0 \\
\hline Chromium & Nanocrystalline & 40.0 \\
\hline Nickel & Nanocrystalline & $19.0^{*}$ \\
\hline
\end{tabular}

* Previously published data (Bhattarai, 1995, 2001).

reported the sputter-deposited ternary Mo-Cr-Ni alloys were also able to be amorphized over a wide composition range when they contained more than 15 at\% nickel ${ }^{23}$. However, the ternary W-Cr-Ni alloys are able to form an amorphous structure over a wide composition range of chromium when the alloys contain 9 at\% or more nickel content. Accordingly, 9 at\% or more nickel addition seems to be sufficient and effective to form an amorphous phase of the sputterdeposited ternary W-Cr-Ni alloys.

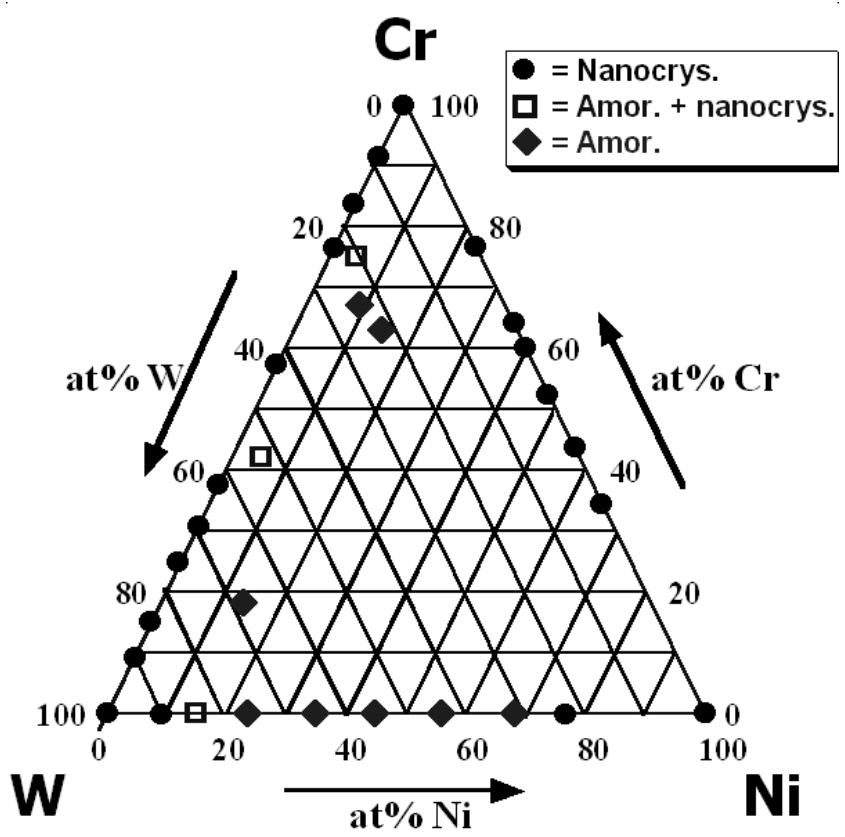

Figure 3: Composition-structure diagram of sputter-deposited W-Cr$\mathrm{Ni}$ alloys.

Figure 4 shows the corrosion rates of the sputter-deposited ternary W-Cr-Ni alloys after immersion for $168 \mathrm{~h}$ in $12 \mathrm{M} \mathrm{HCl}$ solution at $30^{\circ} \mathrm{C}$, open to air. The corrosion rates of the $\mathrm{W}$ $15 \mathrm{Ni}$ alloy, tungsten, chromium and nickel metals are also shown for comparison. The addition of about 21-68 at\% tungsten in the sputter-deposited ternary W-Cr-Ni alloys significantly enhances the corrosion resistance of the alloys in 12 $\mathrm{M} \mathrm{HCl}$ solution. The corrosion rate of the ternary $\mathrm{W}-\mathrm{Cr}-\mathrm{Ni}$ alloys, which are composed of either amorphous or/and nanocrystalline phases, is more than four and three orders of magnitude lower than those of chromium and nickel, respec- 
tively, and even lower than that of sputter-deposited tungsten. The W-18Cr-14Ni and W-42Cr-5Ni alloys showed highest corrosion resistance, that is, about $1 \times 10^{-2} \mathrm{~mm} / \mathrm{y}$ among all the examined ternary $\mathrm{W}$-Cr-Ni alloys after prolong immersion in $12 \mathrm{M} \mathrm{HCl}$ at $30^{\circ} \mathrm{C}$. It is noteworthy to mention here that the corrosion rates of the sputter-deposited binary $\mathrm{W}$ $\mathrm{Ni}^{8,9}$ and $\mathrm{Cr}-\mathrm{Ni}^{23}$ alloys can not exceed those of alloy-constituting elements of the respected alloys in $12 \mathrm{M} \mathrm{HCl}$ solution at $30^{\circ} \mathrm{C}$. However, corrosion rates of the sputter-deposited binary W-Cr alloys were lower than those of tungsten and chromium in $12 \mathrm{M} \mathrm{HCl}$ solution at $30^{\circ} \mathrm{C}^{2,10}$. It had been reported that the sputter-deposited $\mathrm{Cr}-\mathrm{Ni}^{23}, \mathrm{~W}-\mathrm{Ni}^{8,9}$ and $\mathrm{W}-\mathrm{Cr}^{2,10}$ alloys showed the corrosion rates in the range of $10^{1}, 4 \times 10^{-}$ ${ }^{2}$ and $5 \times 10^{-3} \mathrm{~mm} / \mathrm{y}$, respectively, in $12 \mathrm{M} \mathrm{HCl}$ solution. It can, therefore, be said that both tungsten and chromium metals enhances the corrosion resistance of the sputter-deposited ternary W-Cr-Ni alloys synergistically. However, a small addition of nickel seems to be detrimental effect in the corrosion resistance properties of the $\mathrm{W}-\mathrm{Cr}-\mathrm{Ni}$ alloys in $12 \mathrm{M} \mathrm{HCl}$ solution.

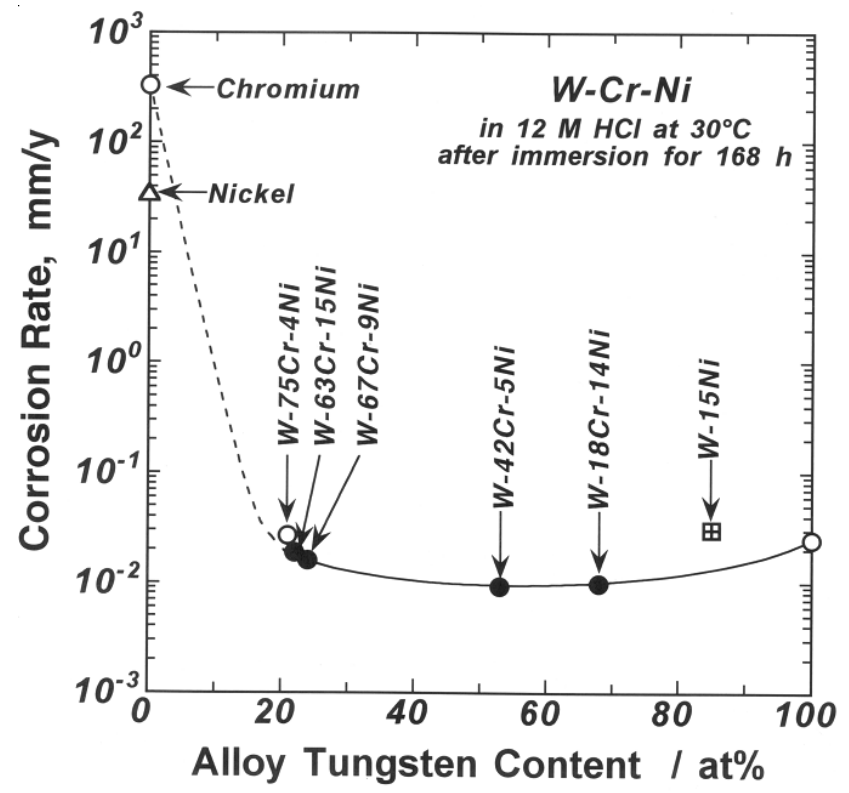

Figure 4: Corrosion rates of sputter-deposited W-Cr-Ni alloys including those of sputter-deposited tungsten, chromium and nickel in $12 \mathrm{M}$ $\mathrm{HCl}$ at $30^{\circ} \mathrm{C}$, open to air.

Electrochemical measurements were carried out for a better understanding of the passivation behavior and high corrosion resistance properties of the sputter-deposited ternary W-Cr$\mathrm{Ni}$ alloys. Figure 5 shows potentiodynamic cathodic and anodic polarization curves for the sputter-deposited W-Cr$\mathrm{Ni}$ alloys in $12 \mathrm{M} \mathrm{HCl}$ solution at $30^{\circ} \mathrm{C}$, open to air. The polarization curves of the sputter-deposited tungsten, chromium and nickel metals are also shown for comparison. All the examined W-Cr-Ni alloys as well as the tungsten metal are spontaneously passivated in this aggressive solution in contrast to chromium and nickel metals those show the activepassive transitions. Furthermore, chromium metal shows the transpassive dissolution at about $0.80 \mathrm{~V}$ (SCE) mostly due to the formation of hexavalent chromium ion. The anodic current densities of the ternary $\mathrm{W}-\mathrm{Cr}-\mathrm{Ni}$ alloys decrease with increasing the chromium content in the alloys, and the $\mathrm{W}$ -
75Cr-4Ni alloy shows the lowest anodic passive current density among the examined alloys in this study. It is noteworthy to mention that the anodic current densities of the alloys are significantly lower than those of the alloyconstituting elements (that is, tungsten, chromium and nickel). Accordingly, the protective quality of the anodic passive films formed on the sputter-deposited ternary W-Cr-Ni alloys is better than those of alloy-constituting elements even in very aggressive environment of $12 \mathrm{M} \mathrm{HCl}$ solution at $30^{\circ} \mathrm{C}$, open to air.

The open circuit potentials of all the examined W-Cr-Ni alloys except the $\mathrm{W}-75 \mathrm{Cr}-4 \mathrm{Ni}$ alloy are located between those of chromium, nickel and tungsten metals, but mostly very close to that of tungsten. The open circuit potential of the W-75Cr4Ni alloy is shifted to more positive direction than those of alloy-constituting elements. Furthermore, the open circuit potentials of the $\mathrm{W}$-Cr-Ni alloys except the $\mathrm{W}-75 \mathrm{Cr}-4 \mathrm{Ni}$ alloy are located very close to the passive regions of chromium metal and the active regions of nickel metal as shown in Fig. 5. Accordingly, the addition of chromium and tungsten enhance the corrosion resistance properties of the sputterdeposited ternary W-Cr-Ni alloys, and such a beneficial effect of nickel metal can not observed as described in Fig. 4 also.

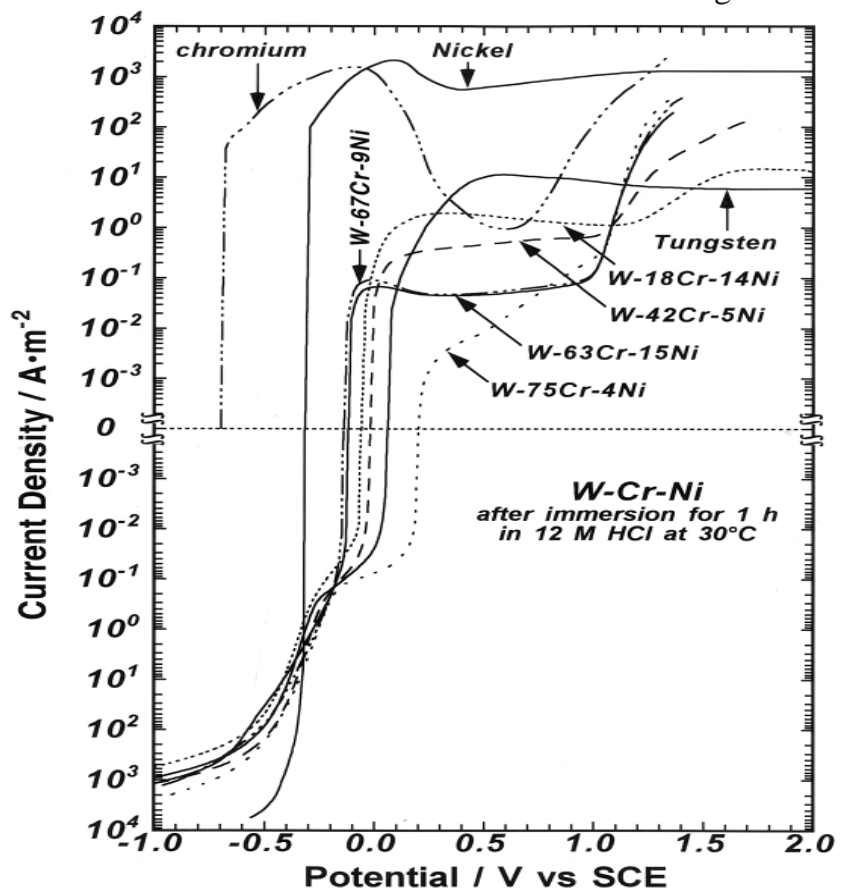

Figure 5: Potentiodynamic anodic and cathodic polarization curves for sputter-deposited W-Cr-Ni alloys measured after immersion for $1 \mathrm{~h}$ in $12 \mathrm{M} \mathrm{HCl}$ solution at $30^{\circ} \mathrm{C}$, open to air. The polarization curves for sputtered tungsten, chromium and nickel metals are also shown for comparison.

\section{CONCLUSIONS}

Amorphous or/and nanocrystalline supersaturated solid solutions of the W-Cr-Ni ternary alloys are successfully prepared by direct current (D. C.) magnetron sputtering and their corrosion behavior is examined by using corrosion tests and electrochemical measurements in $12 \mathrm{M} \mathrm{HCl}$ solution at $30^{\circ} \mathrm{C}$,open to air. The following conclusions are drawn from the results: 
1. The ternary amorphous or/and nanocrystalline W-Cr-Ni alloys exhibit a higher corrosion resistance than that of the binary amorphous or/and nanocrystalline W-Ni alloys and show lower corrosion rates than those of alloy-constituting elements. In particular, the additions of 18 at $\%$ or more chromium contents to the $\mathrm{W}-(4-15) \mathrm{Ni}$ alloys decrease significantly the corrosion rates of the ternary W-Cr-(415)Ni alloys even for prolong immersion in $12 \mathrm{M} \mathrm{HCl}$ solution.

2. The addition of chromium to the sputter-deposited W-Ni alloys leads to a remarkable ennoblement of the open circuit potential, which is in the passive regions of chromium and active regions of nickel metal in $12 \mathrm{M} \mathrm{HCl}$ solution. Consequently, the addition of chromium is effective in improving the corrosion resistance of the sputter-deposited ternary W-Cr-Ni alloys containing small amounts of nickel (that is, 15 at\% or less nickel).

\section{ACKNOWLEDGEMENTS}

The author is very thankful to Professor Emeritus Dr. K. Hashimoto of Tohoku Institute of Technology and Professor Emeritus Dr. K. Asami of IMR of Tohoku University, Sendai, Japan for their kind permission to use the sputtering and XRD machines. Sincere thanks to the Head of Central Department of Chemistry, Tribhuvan University, Kirtipur, Nepal for providing the available research facilities to conduct this research work.

\section{REFERENCES}

1. Bhattarai, J., Akiyama, E., Habazaki, H., Kawashima, A., Asami, K. and Hashimoto, K. 1995. Corrosion Science. 37: 2071-2086.

2. Bhattarai, J. 1998. Tailoring of Corrosion-Resistant Tungsten Alloys by Sputtering, Doctoral Thesis, Department of Materials Science, Faculty of Engineering, Tohoku University, Japan. Pp. 229.

3. Bhattarai, J. 2000. Journal of Nepal Chemical Society. 19: 32-41.

4. Bhattarai, J. 2002. Nepal Journal of Science and Technology. 4: 37-43.

5. Hashimoto, K., Bhattarai, J., Li, X.Y., Park, P.Y., Kim, J.H., Akiyama, E., Habazaki, H., Kawashima, A., Asami, K. and Shimamura, K. 1998. in Proc. of the Special Symposium on Passivity and its Breakdown (eds. P. M. Natishan, H. S. Isaacs, M. Janik-Czachor, V. A. Macagno, P. Marcus and M. Seo). The Electrochemical Society Inc., Pennington, USA. Pp. 369-383.

6 Bhattarai, J., Akiyama, E., Habazaki, H., Kawashima, A., Asami, K. and Hashimoto, K. 1997. Corrosion Science. 39: 353-375.
7. Bhattarai, J., Kawashima, A., Asami, K. and Hashimoto, K. 2000. in Proc. $3^{\text {rd }}$ National Conference on Science and Technology, RONAST (now NAST), Kathmandu, Nepal. 1: 389-407.

8. Bhattarai, J. 1995. The Corrosion Behavior of Sputter-deposited Tungsten-base Alloys. Research Reports, Institute for Materials Research (IMR), Tohoku University, Sendai, Japan. Pp. 43+IV.

9. Bhattarai, J. 2001. Journal of Nepal Chemical Society. 20: 24-40.

10. Bhattarai, J., Akiyama, E., Habazaki, H., Kawashima, A., Asami, K. and Hashimoto, K. 1998. Corrosion Science. 40: 155-175.

11. Bhattarai, J. and Hashimoto, K. 1998. Tribhuvan University Journal. 21(2): 1-16.

12. Bhattarai, J. 2000. Journal of Nepal Chemical Society. 19: 1-14.

13. Bhattarai, J. 2002. Journal of Institute of Science and Technology. 12: $125-138$.

14. Bhattarai, J., Akiyama, E., Habazaki, H., Kawashima, A., Asami, K. and Hashimoto, K. 1998. Corrosion Science. 40: 19-42.

15. Bhattarai, J., Akiyama, E., Habazaki, H., Kawashima, A., Asami, K. and Hashimoto, K. 1998. Corrosion Science. 40: 1897-1914.

16. Jha, H. and Bhattarai, J. 2008. J. Alloys \& Compounds, 456: 474-478.

17. Bhattarai, J., Akiyama, E., Habazaki, H., Kawashima, A., Asami, K. and Hashimoto, K. 1998. Corrosion Science. 40: 757-779.

18. Bhattarai, J. 2006. Journal of Nepal Chemical Society. 21: 19-25.

19. Zarzycki, J. 1991. Materials Science and Technology; A Comprehensive Treatment (eds R. W. Chan, P. Haasen and E. J. Kramer), VCH Publishers Inc., New York. 9: 91.

20. Sah, S.P. 2005. Corrosion Behavior of Sputter-Deposited Nanocrystalline W-Ni Alloys in Neutral and Alkaline Solutions, M. Sc. Dissertation, Central Department of Chemistry, Tribhuvan University, Kathmandu, Nepal. Pp. 59+IV.

21. Bhattarai, J., Sah, S. P. and Jha, H. 2007. Journal of Nepal Chemical Society. 22: 7-16.

22. Sah, S.P. and Bhattarai, J. 2008/2009. Journal of Nepal Chemical Society. 23: 45-53.

23. Park, P. Y., Akiyama, E., Habazaki, H., Kawashima, A., Asami, K. and Hashimoto, K. 1994. Corrosion Science. 36: 1395-1410.

24. Akiyama, E., Habazaki, H., Kawashima, A., Asami, K. and Hashimoto, K. 1996. Corrosion Science. 38: 279-292.

25. Cullity, B.D. 1977. Elements of X-ray diffraction, $2^{\text {nd }}$ edition, Addison-Wesley Publ. Co., Inc., USA. Pp. 101.

26. Niessen, A. K., Doer, F. R. de, Boom, R., Chatel, P. F. de, Mattena, W. C. M. and Miedema, A. R. 1983. Calphad. 7: 51. 